\title{
Divertículo de Zenker como causa de disfagia en el anciano
}

\author{
Sr. Director:
}

Los síntomas referidos al aparato digestivo alto constituyen un motivo muy frecuente de consulta en los ancianos, sobre todo en aquellos pacientes con pluripatologías crónicas, somatizadores o afectos de cuadros depresivos. Las dificultades de abordaje de este tipo de pacientes, junto con una cierta tendencia a atribuir a la esfera psicoafectiva cualquiera de sus múltiples quejas, nos hacen correr el riesgo de pasar por alto procesos orgánicos potencialmente graves. Una actitud de escucha activa, una exploración clínica rigurosa y la práctica de las exploraciones complementarias que procedan, son inexcusables en este tipo de pacientes.

\section{OBSERVACIÓN CLÍNICA}

Mujer de 76 años de edad, entre cuyos antecedentes personales destacan los siguientes: en 1994 sufrió una pancreatitis aguda de origen biliar, siendo sometida a colecistectomía. En el curso del estudio preoperatorio se detectó una anemia megaloblástica que se trató con vitamina B12. En 1997 presentó una diverticulitis sigmoidea perforada que exigió la práctica de sigmoidectomía parcial, con colostomía temporal que mantuvo durante dos años. A raíz de ello, presentó un episodio depresivo mayor que culminó con un intento de suicidio en 1999. Ese mismo año fue reintervenida para restablecer la continuidad intestinal, estando desde entonces sometida a tratamiento antidepresivo y bajo el control del Equipo de Salud Mental de nuestro Centro. 
En enero de 2000 consulta, acompañada por un familiar, y refiere insomnio de despertar precoz, empeoramiento del estado de ánimo con tendencia al llanto, y una batería de síntomas digestivos poco específicos: "tengo menos apetito, todo lo que como me sienta fatal, se me hace un nudo en la garganta, siempre tengo mal sabor de boca,...". El episodio se interpretó como una reagudización de su cuadro depresivo, remitiéndose para valoración a su psiquiatra.

Durante los últimos meses de 2000 y primeros de 2001 recurrió en varias ocasiones al servicio de Urgencias Domiciliarias por presentar atragantamiento durante las comidas, que se resuelve de forma espontánea antes de la llegada del equipo sanitario. Tras uno de esos episodios presentó una neumonía para la que se prescribió tratamiento antibiótico, citando a la paciente para valoración al término del mismo.

A la exploración se encuentra bradipsíquica, con buena orientación temporoespacial. Muestra ligera palidez cutaneomucosa. Refiere que la noche anterior tuvo un episodio de pirosis retrosternal que mejoró poco con un antiácido. Ante la sospecha clínica de reflujo gastroesofágico se solicitó un tránsito baritado esofagogastroduodenal, que mostró los siguientes hallazgos (Figs. 1 y 2): gran divertículo de Zenker con incoordinación faringoesofágica que provoca paso de contraste al árbol respiratorio. También se observa un pequeño divertículo por tracción en porción distal del esófago. Síndrome de esófago corto y hernia de hiato por deslizamiento con evidentes signos de reflujo gastroesofágico.

\section{DISCUSIÓN}

El divertículo faringoesofágico posterior o divertículo de Zenker (DZ) fue descrito por primera
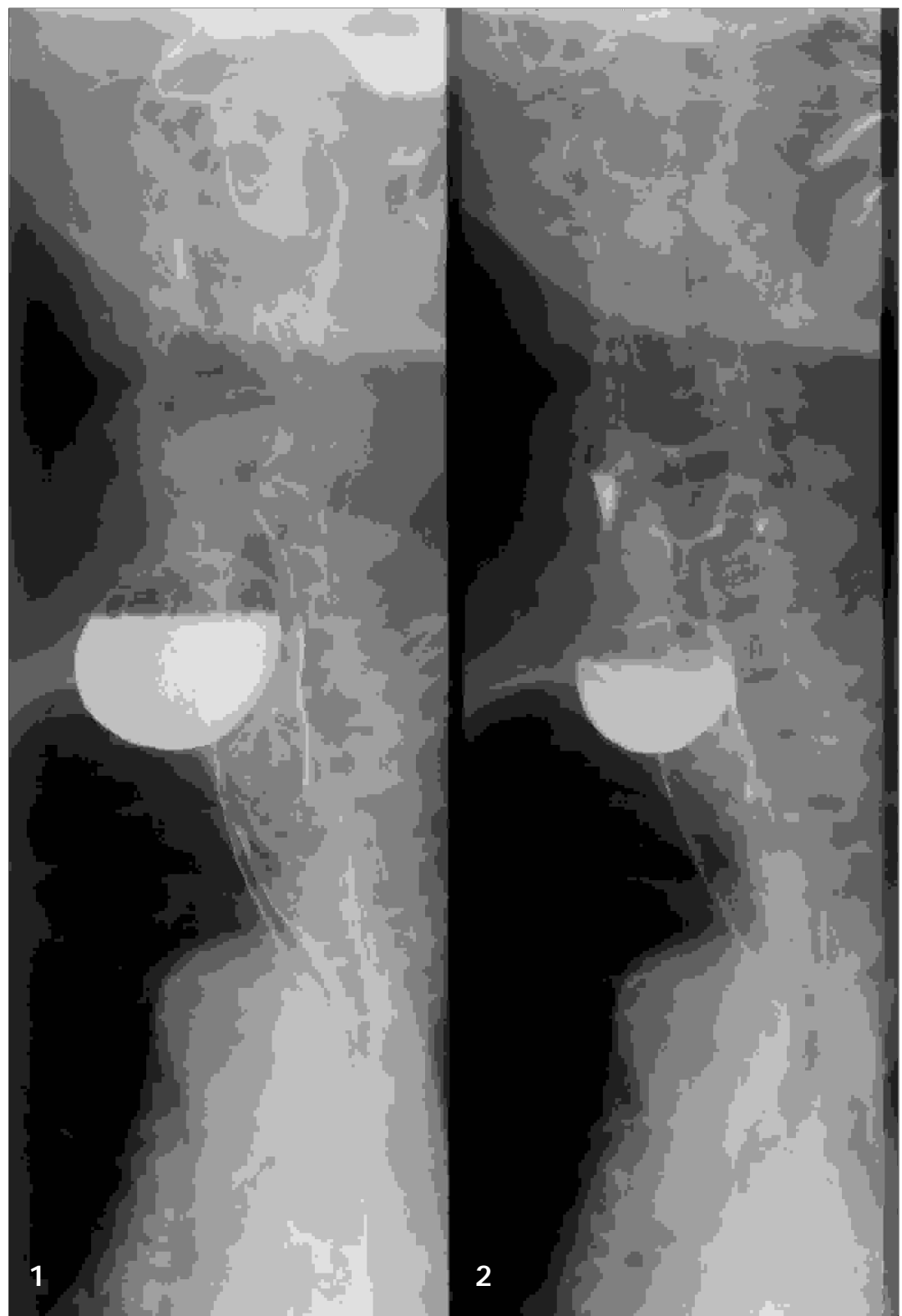

Figuras 1 y 2

vez por Ludlow en 1764, aunque toma el nombre del autor de la primera serie de casos, publicada por Zenker en $1878^{1}$. Consiste en la herniación de la mucosa hipofaríngea a través de una zona de baja resistencia, limitada por el esfínter cricofaríngeo y las fibras oblicuas del músculo constrictor de la faringe inferior, conocida como triángulo de Killian ${ }^{2}$. Se trata de una alteración poco frecuente, que se encuentra aproximadamente en el $1 \%$ de los esofagogramas baritados y tiene su máxima incidencia en hombres a partir de los 70 años.

Se han propuesto múltiples teorías fisiopatológicas para explicar la formación de los DZ, y la controversia persiste en la literatura internacional. En condiciones normales, el esfínter esofágico superior (EES) se relaja durante la deglución, y se contrae una vez que el movimiento peristáltico ha hecho avanzar el bolo más allá del propio esfínter. Algunos autores sostienen que un defecto en la relajación del EES po- 
dría estar en la base de la formación del DZ, aunque los estudios manométricos no han proporcionado resultados concluyen- tes ${ }^{1,3,4}$. Otros estudios sugieren un problema neurológico de base, al encontrar una asociación con la enfermedad cerebrovascular o con neuropatías periféricas 5 . Por otro lado, se han invocado factores bioquímicos, al encontrar diferencias en el contenido de colágeno y elastina en el músculo cricofaríngeo en pacientes con o sin $\mathrm{DZ}^{6}$.

En cualquier caso, sí hay acuerdo en que el DZ aparece con mayor frecuencia en pacientes con otra patología gastroesofágica asociada, fundamentalmente el reflujo gastroesofágico, aunque también se ha descrito su asociación con el vólvulo gástrico ${ }^{7}$.

El diagnóstico de sospecha debe establecerse ante cualquier paciente anciano con clínica de disfagia, regurgitación, halitosis, sensación de cuerpo extraño o episodios recurrentes de atragantamiento. La confirmación diagnóstica exige la práctica de un tránsito baritado, exploración inocua y de alta rentabilidad diagnóstica. La endoscopia diagnóstica es desaconsejada por la mayoría de los autores por la posibilidad de introducción del endoscopio dentro del divertículo. También se ha usado la ecografía, aunque se ha descrito la confusión de un DZ con un nódulo tiroideo $^{8}$.
Las complicaciones descritas incluyen la hemorragia, asociada en una ocasión a la ingesta diaria de aspirina que quedaba alojada en el divertículo, la presencia de un carcinoma escamoso en el seno del DZ o, más frecuentemente, las neumonías de repetición por aspiración? ${ }^{7}$.

El tratamiento quirúrgico del DZ ha evolucionado en los últimos años en el aspecto técnico, pero sigue estando basado en la miotomía cricofaríngea, asociada a la escisión del divertículo o a la diverticulopexia ${ }^{3}$. Actualmente se prefiere la técnica endoscópica, que ha demostrado menor tasa de complicaciones y acortamiento del tiempo de hospitalización. Es necesario hacer notar que, pese a la avanzada edad de la mayoría de los pacientes y la frecuente patología asociada, la corrección quirúrgica del DZ se ha demostrado eficaz, segura y capaz de mejorar la calidad de vida de los pacientes.

Pese a ello, en nuestro caso, una vez explicadas las distintas alternativas a la familia, ésta rehusó la intervención.

\section{G. González Roa, J. Palma La- fuente*, G. M. Ramos Gallego, F. Sarmiento Jiménez*}

Médicos de Familia. Centro de Salud de Vélez-Málaga Norte y
Sur. *Distrito Sanitario de la Axarquía. Málaga

\section{BIBLIOGRAFÍA}

1. Stockli SJ, Schmid ST. Das Zenkersche divertikel. Schweiz Med Wochenschr 2000; 130(16): 590-6.

2. Harford WV. Divertículos de la hipofaringe y el esófago, el estómago y el intestino delgado. En: Feldman M, Scharschmidt BF, Sleisinger MH, editores. Enfermedades gastrointestinales y hepáticas. $6^{a}$ ed. Buenos Aires: Editorial Médica Panamericana, 2000; 334-6.

3. Vescio G, Battaglia M, Galleli G, Sommella L, Vetere A, Natale R. Zenker's diverticulum. A propos a case. Ann Ital Chir 2000 Jul-Aug; 71 (4): 507-10.

4. Peters JH, Mason R. The physiological basis for the Zenker's diverticulum. Chirurg 1999 Jul; 70 (7): 741-6.

5. Walters DN, Battle JW, Portera CA, Blizzard JD, Browder IW. Zenker's diverticulum in the elderly: A neurologic etiology? Am Surg 1998; 64(9): 909-11.

6. Venturi M, Bonavina L, Colombo L, Antoniazzi L, Bruno A, Mussini E, et al. Biochemical markers of upper esophageal sphincter compliance in patients with Zenker's diverticulum. J Surg Res 1997; 70 (1): 46-8.

7. Marini L, Azarian R, Gagnadoux F, Brion N, Petitpretz P. Volvulus gastrique associé a un diverticule de Zenker: une cause rare de pneumopathie recidivante. Rev Mal Respir 2000; 17 (1): 121-3.

8. Kumar A, Aggarwal S, Pham DH. Pharyngoesophageal (Zenker's) diverticulum mimicking thyroid nodule on ultrasonography: Report of two cases. J Ultrasound Med 1994; 13 (4): 319-22. 